\title{
Jorge Luis Borges, epistemólogo. Una lectura en el espejo (y los laberintos) de las ciencias sociales
}

\section{Jorge Luis Borges, Epistemologist. A Reading in the Mirror (and the Labyrinths) of the Social Sciences}

\section{Martín Retamozo*}

RESUMEN: Este artículo se ocupa de algunos problemas actuales de la epistemología de las ciencias sociales en textos de Jorge Luis Borges. A partir de un conjunto de textos y de figuras propias del universo borgeano, se plantean analogías con problemas ontológicos (la relación de lo infinito con el orden), metodológicos (las maneras de conocer lo plural) y comunicacionales (la capacidad del lenguaje para transmitir el saber). A treinta años de su fallecimiento, este trabajo también es un homenaje al mayor escritor argentino.

Palabras Clave: Epistemología; Jorge Luis Borges; Metodología; Literatura.

ABSTRACT: This article aims to reflect about some current epistemological problems of social sciences, based on texts written by Jorge Luis Borges. I propose analogies between a set of texts belonging to the writer and ontological problems (the relationship among the infinity and the order), methodological problems (different ways of knowing the diversity) and communication problems (language's ability to transmit knowledge). Thirty years after the death of Borges, this work is also a tribute to the greatest Argentine writer.

KEY wORDS: Epistemology; Jorge Luis Borges; Methodology; Literature.

Recibido: 10 de agosto de 2018

Aceptado: 12 de noviembre de 2018

Universidad Nacional de la Plata, CONICET (martin.retamozo@gmail.com). Este trabajo es resultado de la estancia de investigación en el Llilas Benson de la Universidad de Texas (Austin-Estados Unidos) financiada por el conicET. Agradezco a Javier Auyero por el apoyo durante la misma. Verónica Capasso, Olga Bracco y Belén Morris contribuyeron con valiosos comentarios a versiones anteriores de este trabajo, mi reconocimiento y exculpación. 
Todo es símbolo, hasta el dolor más desgarrador J. L. Borges, El espejo de los enigmas

\section{INTRODUCCIÓN}

TC orge Luis Borges es, sin duda, el escritor argentino más trabajado por la crítica literaria mundial y es difícil tener el coraje - palabra tan borgeana- de escribir sobre él. ${ }^{1}$ Como nosotros preferimos escribir sobre una mesa (el chiste le pertenece a Dalmiro Sáenz [1983]) abandonaremos esa empresa antes de intentarla. Más modesto, nuestro trabajo se propone mostrar ciertos problemas de epistemología de las ciencias sociales, tan clásicos como frecuentemente olvidados, despreciados o infamados, pero con la refinada compañía de Georgie. Esta travesía ocurre en un contexto en que muchos científicos sociales creen, como los hombres de Tlön, que la metafísica (y la filosofía en general) pertenece a un subgénero de la literatura fantástica, y abundan científicos duros (y funcionarios) a los que les parece teología. ${ }^{2}$ No nos guía la mera pretensión de hedonismo ilustrado sino la convicción de la relevancia de estos asuntos. En efecto, la espectral presencia de algunos problemas clásicos a la hora de plantear estudios en el campo de las ciencias sociales, atormenta a los investigadores que tienen la desgracia de percibirlos y, con particular placer, a los tesistas de posgrado. En un terreno post-metafísico, post-empirista y post-fundacional, un conjunto significativo de debates epistemológicos encuentran aquí otros términos para comprenderlos, claro, con la ayuda de algunos espejos provistos por Borges.

1 The Borges Center, en la Universidad de Pittsburgh (http://www.borges.pitt.edu) es uno de los laberintos más destacados en los que cada enlace conduce, como una puerta, a salas infinitas, todas repletas de diferentes versiones de Borges. Esta es, sin embargo, sólo una de las salas del pluriverso de escritos sobre el autor.

2 El primer ministro de Ciencia y Tecnología de Argentina, Lino Barañao expresó en un reportaje que "a veces los trabajos en ciencias sociales me parecen teología" (Veiras y Moledo 2008), las críticas y regaños epistemológicos, por supuesto, no tardaron en llegar de la pluma de Rubén Dri, Norma Giarraca, Horacio González, Atilio Boron y Eduardo Grüner, entre otros, publicadas en el mismo medio. 
Borges ha ejercido una fascinación en el campo del pensamiento: recordemos que fue traducido por la revista dirigida por Jean Paul Sartre en 1955; ${ }^{3}$ fue referido por Lacan en el célebre seminario sobre "La carta robada"; movió a risa a Foucault en el prefacio de Las palabras y las cosas (1966) y aparece en uno de los últimos trabajos de Žižek (2012) sobre Hegel (aunque también existen ciertas críticas como las de Deleuze ${ }^{4}$ Guattari en su Mil mesetas), por citar sólo unos ejemplos. Además, ha sido, por supuesto, objeto privilegiado de la crítica cultural latinoamericana (Sarlo 2007). Sin embargo, Borges siempre se declaró - con falsa modestia - un mero lector de antologías y enciclopedias en las que buscaba menos información y erudición que estímulos literarios. ${ }^{5}$ Este escrito, entonces, no busca enjuiciar su lectura de filósofos como Platón, Spinoza, Berkley, Hume, Schopenhauer o Russel (quizás sus preferidos), ni realizar una arqueología de una presunta teoría detrás de su universo literario. ${ }^{6} \mathrm{Ni}$ siquiera, en rigor, trata sobre Borges, sino que busca poner en espejo algunas intervenciones borgeanas y ciertos problemas de la epistemología de las ciencias sociales contemporáneas, con la finalidad de escudriñarlas desde otra perspectiva. En este horizonte plantearemos tres campos en los que

3 El número doble de junio-julio de 1955 contiene la traducción de "El idioma analítico de John Wilkins" (junto a otros textos); tres años antes René Étiemble le había dedicado "Un homme à tuer: Jorge Luis Borges, cosmopolite", en la misma revista. Recordemos que Ficciones se tradujo en 1951 al francés. Para una revisión de la relación de Borges con el pensamiento francés, véase Lema-Hincapié (2005).

4 Deleuze también refiere, de modo más benévolo, a Borges en La lógica del sentido y Diferencia y repetición.

5 Si concedemos credibilidad a las palabras del autor podemos comprender la aparición en su obra de pasajes factibles de asociar con posturas filosóficas como el panteísmo, el nominalismo, el nihilismo, el pragmatismo, el idealismo, el posmodernismo, el escepticismo.

6 Para una revisión breve de la controversia sobre Borges y la filosofía occidental ver Lema-Hincapié (2011), también Mateos y García (1998), y la excelente compilación de Alfonso de Toro y Fernando de Toro (1999). Ezequiel de Olaso sugiere "no buscar el pensamiento de Borges tras sus ficciones sino, al revés, descubrir ciertos ocultos criterios poéticos que orientan su atracción por determinados pensamientos. Borges celebra la especulación como una admirable posibilidad literaria. Lo que busca es la poesía del pensamiento" (1999: 18). Bosteels (2007) sigue una distinción lacaniana, y lo ubica como un antifilósofo. 
podemos reflejar problemas de epistemología de las ciencias sociales en clave posestructuralista: el problema de la realidad social, el lenguaje y la construcción del objeto.

"TOTALIDAD E INFINITO". DERIVAS SOBRE EL UNIVERSO

La idea de lo infinito, que no es a su vez una representación de lo infinito, es la fuente común de la actividad y la teoría

(E. Levinas, Totalidad e infinito)

Las cuestiones ontológicas no gozan de muy buena prensa en el campo de las ciencias sociales (y son un anatema en la ciencia política); han sido confinadas, con suerte, a alguna unidad del programa de Metafísica en las carreras de Filosofía. No obstante, a contracorriente, en los últimos años, enfoques como el realismo crítico y la teoría morfogenética de Margaret Archer vienen recuperando estos asuntos para las ciencias sociales, en un diálogo crítico con autores como Anthony Giddens y Pierre Bourdieu (Lawson et al. 2013). Reparar en cuestiones referidas a la ontología de lo social no obedece a un gesto de vana erudición, sino que se trata de evitar caer en versiones del realismo ingenuo, de la unidimensionalidad de lo social, propio de un positivismo prepopperiano que suele inundar los trabajos. Por nuestra parte, elegimos exponer ciertas posiciones en los debates epistemológicos que se incluyen en lo que, a grandes rasgos, podemos denominar pensamiento político posfundacional (Marchart 2007). Borges será nuestro Virgilio. ${ }^{7}$

Ubicados en este terreno como clave de lectura, como un espejo, podemos imaginar cómo Borges formula de múltiples maneras la tesis ontológica del posestructuralismo sobre la infinitud de lo social, la heterogeneidad y la relación orden/caos. Universo e infinito son dos tópicos bor-

Para un estudio detallado de concepciones ontológicas en la obra de Borges: William Bossart (2003), especialmente el capítulo 1 donde se reconstruyen aspectos ontológicos de la vida cotidiana. 
geanos centrales para nuestro propósito, ya que lidian con los problemas que nos interesan. En "El Aleph", quizás su cuento más famoso, intenta poner en lenguaje la multiplicidad constitutiva del mundo:

Vi el populoso mar, vi el alba y la tarde, vi las muchedumbres de América, vi una plateada telaraña en el centro de una negra pirámide, vi un laberinto roto (era Londres), vi interminables ojos inmediatos escrutándose en mí como en un espejo, vi todos los espejos del planeta y ninguno me reflejó, vi en un traspatio de la calle Soler las mismas baldosas que hace treinta años vi en el zaguán de una casa en Fray Bentos, vi racimos, nieve, tabaco, vetas de metal, vapor de agua, vi convexos desiertos ecuatoriales y cada uno de sus granos de arena, vi en Inverness a una mujer que no olvidaré, vi la violenta cabellera, el altivo cuerpo, vi un cáncer en el pecho, vi un círculo de tierra seca en una vereda, donde antes hubo un árbol, vi una quinta de Adrogué, un ejemplar de la primera versión inglesa de Plinio, la de Philemon Holland, vi a un tiempo cada letra de cada página (de chico, yo solía maravillarme de que las letras de un volumen cerrado no se mezclaran y perdieran en el decurso de la noche), vi la noche y el día contemporáneo, vi un poniente en Querétaro que parecía reflejar el color de una rosa en Bengala, vi mi dormitorio sin nadie, vi en un gabinete de Alkmaar un globo terráqueo entre dos espejos que lo multiplican sin fin, vi caballos de crin arremolinada, en una playa del Mar Caspio en el alba, vi la delicada osatura de una mano, vi a los sobrevivientes de una batalla, enviando tarjetas postales, vi en un escaparate de Mirzapur una baraja española, vi las sombras oblicuas de unos helechos en el suelo de un invernáculo, vi tigres, émbolos, bisontes, marejadas y ejércitos, vi todas las hormigas que hay en la tierra, vi un astrolabio persa, vi en un cajón del escritorio (y la letra me hizo temblar) cartas obscenas, increíbles, precisas, que Beatriz había dirigido a Carlos Argentino, vi un adorado monumento en la Chacarita, vi la reliquia atroz de lo que deliciosamente había sido Beatriz Viterbo, vi la circulación de mi oscura sangre, vi el engranaje del amor y la modificación de la muerte, vi el Aleph, desde todos los puntos, vi en el Aleph la tierra, y en la tierra otra vez el Aleph y en el Aleph la tierra, vi mi cara y mis vísceras, vi tu cara, y sentí vértigo y lloré, porque mis ojos habían visto ese objeto secreto y conjetural, cuyo nombre usurpan los hombres, pero que ningún hombre ha mirado: el inconcebible universo (Borges 1974: 625-626). 
La noción de infinitud ${ }^{8}$ es central en la concepción del universo y se plasma en metáforas como los libros, los espejos y los laberintos: "La línea consta de un número infinito de puntos; el plano, de un número infinito de líneas; el volumen, de un número infinito de planos; el hipervolumen, de un número infinito de volúmenes" comienza "El Libro de arena" con el agregado de que el número de páginas de ese libro es precisamente infinito: "Ninguna es la primera; ninguna la última. No sé por qué están numeradas de ese modo arbitrario. Acaso para dar a entender que los términos de una serie infinita admiten cualquier número" y un despliegue infinito del infinito. En "La busca de Averroes" lo formula de la siguiente manera: "Infinitas cosas hay en la tierra; cualquiera puede equipararse a cualquiera. Equiparar estrellas con hojas no es menos arbitrario que equipararlas con peces o con pájaros" (1974: 586). En este sentido el infinito postulado para la reflexión ontológica abre a la pregunta por el arkbé y oficia de posibilidad e imposibilidad del pensamiento, impulsa la búsqueda de decodificarlo y termina por develar la ausencia de criterios subyacentes (fundamentos). En "Avatares de la tortuga" "Hay un concepto que es el corruptor y el desatinador de los otros. No hablo del Mal, cuyo limitado imperio es la ética, hablo del infinito. Yo anhelé compilar alguna vez su móvil historia" (1974: 254). Incluso, esta última cita pone en cuestión indirecta y anacrónicamente a Emmanuel Levinas a quien invocamos en el título de esta sección que consideraba a la ética como la filosofía primera (el pensamiento político posfundacional, por su parte, propondrá a la filosofía política como protofilosofía). El problema del Bien tiene un terreno donde dirimirse - la ética - pero el problema del infinito rebasa sus espacios de dominio. El problema, claro, es quién ordena ese caos. En el poema "Ajedrez", que como el otro es un juego infinito, Borges lo deja claro:

8 Borges explica su descubrimiento del infinito: "Debo mi primera noción del problema del infinito a una gran lata de bizcochos que dio misterio y vértigo a mi niñez. En el costado de ese objeto anormal había una escena japonesa; no recuerdo los niños o guerreros que la formaban, pero sí que en un ángulo de esa imagen la misma lata de bizcochos reaparecía con la misma figura y en ella la misma figura, y así (a lo menos, en potencia) infinitamente" (Borges 1986: 6). 
Dios mueve al jugador, y éste, la pieza.

¿Qué Dios detrás de Dios la trama empieza

de polvo y tiempo y sueño y agonía? (1974: 813).

La figura de Dios es omnipresente en la obra de Borges y a la vez una hipótesis vana, un recurso literario. ${ }^{9}$ El supuesto es el infinito, la totalidad siempre desbordada pero que requiere de un fundamento contingente para detener el regreso al infinito e instaurar la causa primera que en su literatura es Dios, como en Spinoza y, quizás a su pesar, Hegel. El problema es triple: la morfología del infinito, ${ }^{10}$ el estatus del fundamento y el modo de conocer, comprender y decir lo infinito. ${ }^{11}$

El pensamiento posfundacional, precisamente, parte de la aniquilación de cualquier principio trascendente que se proponga como fundamento de lo inmanente: muerto Dios, tal como lo enuncia Nietzsche, abandonada la inaccesible naturaleza humana y, finalmente, sembrada la desconfianza en la razón universal (otra diosa) no quedan más alternativas que construir precarios fundamentos humanos (demasiado humanos). En el pensamiento posfundacional, de acuerdo con Oliver Marchart (2007), existen dos situaciones que muestran la falla de la estructura (de allí la idea de posestructuralismo). Por un lado, la tesis clásica -que Borges enuncia con precisión- del exceso infinito que jaquea cualquier intento de someter lo heterogéneo en los límites de algo dado y pleno. En palabras de Laclau (1983), "Frente a esta visión esencialista, hoy día tendemos a aceptar la infinitud de lo social, es decir, el hecho de que todo sistema estructural es limitado, que está siempre rodeado por un 'exceso de sentido' que él es incapaz de dominar y que, en consecuencia, la 'sociedad'

9 En una entrevista, Malú Sierra se empeña en acercar a Borges a Dios por la presencia de éste en su obra; el escritor le responde que Dios es un recurso literario (https:// www.youtube.com/watch?v=dTAAitLhmzg).

10 Entre los estudiosos de Borges hay una corriente que enfatiza su adscripción al nominalismo (Rest 2009), mientras que otros recuperan la crítica al nominalismo (Stewart 1996). Para una revisión de la controversia al respecto ver Martin (2010).

11 Es cierto que Borges también recurre con frecuencia a la Cábala como el modo de cifrar y descifrar el universo; la atención a este recurso excede el propósito de este trabajo. 
como objeto unitario e inteligible que funda sus procesos parciales, es una imposibilidad" (2000: 104). Castoriadis (1975) también llama a "aceptar la idea de que hay infinito e indefinido [.. . ] sin por ello renunciar al trabajo, que toda determinación racional deja un residuo no determinado y no racional, que el residuo es tan esencial como lo que fue analizado, que necesidad y contingencia están continuamente imbricadas una dentro de la otra" (2007: 89). Para Castoriadis, la instancia "natural" o pre-social es un plexo sobre el cual se apoya la institución de lo social (1986).

Borges lo enuncia en "La biblioteca de Babel": "El universo (que otros llaman la Biblioteca) se componte de un número indefinido, y tal vez infinito, de galerías hexagonales, con vastos pozos de ventilación en el medio, cercados por barandas bajísimas" (1974: 465) y finaliza:

Acabo de escribir infinita. No he interpolado ese adjetivo por una costumbre retórica; digo que no es ilógico pensar que el mundo es infinito. Quienes lo juzgan limitado, postulan que en lugares remotos los corredores y escaleras y hexágonos pueden inconcebiblemente cesar, lo cual es absurdo. Quienes la imaginan sin límites, olvidan que los tiene el número posible de libros. Yo me atrevo a insinuar esta solución del antiguo problema: la biblioteca es ilimitada y periódica. Si un eterno viajero la atravesara en cualquier dirección, comprobaría al cabo de los siglos que los mismos volúmenes se repiten en el mismo desorden (que, repetido, sería un orden: el Orden) (1974: 471).

Lo anterior alimenta la lectura posfundacional de Borges bajo la segunda tesis posestructuralista: la ausencia de un fundamento trascendente y la necesidad de un fundamento contingente que es a su vez imposible en tanto que jamás es completo. En una entrevista recogida en "Borges oral", dice "Quizás el mundo es un laberinto; no lo sabemos... pero la idea del laberinto es consolador[a], porque el laberinto tiene un sentido pero no sabemos si el mundo tiene un centro". ${ }^{12}$ Ernesto Laclau también se refiere a la cuestión: "fijación que es, en última instancia, imposible. Lo social no es tan sólo el infinito juego de las diferencias. Es también el intento de limitar este juego, de domesticar la infinitud, de abarcarla dentro de la

12 En "Borges oral", entrevista con Bernard Pivot, publicada en el diario La Jornada. 
finitud de un orden (Laclau, 2000: 104). En el caso de Borges el atributo del viajero es el tiempo (o su ausencia como eternidad) y desde allíla posibilidad de una repetición, iuna iteración?, que logra un orden que está de alguna manera supuesto en la noción del laberinto. En "Tlön, Uqbar, Orbis Tertius" lo enuncia del siguiente modo: "Tlön será un laberinto, pero es un laberinto urdido por hombres, un laberinto destinado a que lo descifren los hombres" (1974: 443). El historicismo radical está entre nosotros.

En la filosofía política contemporánea, el concepto de "lo políico" busca capturar esa función ontológica de cierre, de dotar de cierto orden, que requiere el poder (como potentia) para instituir una estructuración de relaciones sociales. ${ }^{13}$ La teoría posfundacional, a su vez, identifica esa ausencia del fundamento trascendente como condición de la democracia, como una forma de reconocer la indeterminación de lo humano y la posibilidad a múltiples formas de mundos. Autores como Lefort han denunciado cualquier intento por proponer fundamentos trascendentes que se ponen como anteriores a la comunidad política, y Borges lo refrenda "Hace diez años bastaba cualquier simetría con apariencia de orden -el materialismo dialéctico, el antisemitismo, el nazismo- para embelesar a los hombres" ("Tlön, Uqbar, Orbis Tertius", 1974: 442). Ambos comparten la crítica a los totalitarismos por el intento de poner principios organizativos cerrados y fuera del alcance de los hombres. ${ }^{14}$

Los metafísicos de Tlön argumentan que "un sistema no es otra cosa que la subordinación de todos los aspectos del universo a uno cualquiera de ellos" (1974: 436), seguramente porque ya habían leído a Althusser y el concepto de sobredeterminación que toma de la lingüística y el psicoanálisis (Althusser 1965). En efecto, en la teoría política posfundacional la producción de la sociedad queda ligada a un proceso histórico-político

13 Beatriz Sarlo argumenta que "La pregunta sobre los modos en que el orden se consolida, se conserva o se destruye pertenecen a la dimensión filosófica de la política, que se menciona raramente en relación a Borges" (2007: 68).

${ }_{14} \mathrm{Al}$ respecto Silvia Dapia argumenta: "By exalting or celebrating the power of constructs (vocabularies or encyclopedias) independently of any reality or external source to which they may apply, Borges is gradually erasing the world's own determinacy. The world's shape is the shape of our constructs" (2013: 141). 
que estructura las relaciones sociales. La articulación de elementos a partir de la producción de puntos nodales que amarran (y producen) relaciones sociales es relevante para pensar la sociedad instituida y sus nodos estructurantes del orden (los procesos de posición, inclusión y exclusión en clivajes como clase, género, etnia, propiedad, accesos, ciudadanías, etc.). Esos indicadores de la diferencia, dice Lefort (1990), pasan por el discurso.

La mediación althusseriana nos habilita a considerar las palabras del propio Marx y la cuestión de la totalidad como dimensión ontológica y metodológica:

Lo concreto es concreto porque es la síntesis de múltiples determinaciones, por lo tanto, unidad de lo diverso. Aparece en el pensamiento como proceso de síntesis, como resultado, no como punto de partida, aunque sea el efectivo punto de partida, y, en consecuencia, el punto de partida también de la intuición y de la representación. En el primer camino, la representación plena es volatilizada en una determinación abstracta; en el segundo, las determinaciones abstractas conducen a la reproducción de lo concreto por el camino del pensamiento (1980: 300).

Marx sistematiza, con cierto espíritu hegeliano, ${ }^{15}$ el problema que queremos resituar. La totalidad social como síntesis de lo múltiple (lo heterogéneo, lo infinito), los procesos de conocimiento (científico) y la comunicación.

EL TAMAÑO DE MI ESPERANZA

Borges ha sido caracterizado como un escéptico ${ }^{16}$ a partir del análisis de cuentos como "Tlön, Uqbar, Orbis Tertius" y "Pierre Menard, autor del

15 Recordemos que, en una carta a Engels de principios 1858, Marx hace alusión a que la relectura de la Lógica (le habían regalado un ejemplar que había pertenecido a Bakunin) inspira sus prolegómenos a El Capital.

16 En el epílogo de Otras inquisiciones (1952) Borges dice descubrir su propio escepticismo esencial al evaluar las doctrinas filosóficas y religiosas por su valor estético. 
Quijote"17 o sentencias como "Es aventurado pensar que una coordinación de palabras (otra cosa no son las filosofías) pueda parecerse mucho al universo" ("Avatares de la tortuga", 1974: 258) o "notoriamente no hay clasificación del universo que no sea arbitraria y conjetural. La razón es muy simple: no sabemos qué cosa es el universo" ("El idioma analítico de John Wilkins", 1974: 708) o "No me interesa lo que un hombre pueda trasmitir a otros hombres; como el filósofo, pienso que nada es comunicable por el arte de la escritura" ("La casa de Asterión", 1974: 569). También en "La escritura del dios", cuando Tiznacán, el mago de la pirámide Qaholom preso en una cárcel de piedra, tiene la revelación que no puede transmitir:

Entonces ocurrió lo que no puedo olvidar ni comunicar. Ocurrió la unión con la divinidad, con el universo (no sé si estas palabras difieren). El éxtasis no repite sus símbolos: hay quien ha visto a Dios en un resplandor, hay quien lo ha percibido en una espada o en los círculos de una rosa. Yo vi una Rueda altísima, que no estaba delante de mis ojos, ni detrás, ni a los lados, sino en todas partes, a un tiempo (1974: 598).

La imposibilidad de comunicación es, también, un tema de "El espejo y la máscara", en el que el poeta, luego de escribir un poema encargado por el rey que "No era una descripción de la batalla, era la batalla", avanza aún más y logra acceder a la Belleza para representarla en una sola línea impronunciable. La revelación conduce a la muerte (el poeta se suicida con el último regalo del rey: la daga) y a la locura del otrora rey que deviene en un vagabundo mendigo. En "El etnógrafo", la historia de aquel estudiante estadounidense a quien sus profesores le sugirieron que aprendiera la lengua indígena para estudiar el secreto que los brujos revelan a los iniciados, la idea del acceso a una verdad que no puede ser transmitida es central en el desenlace. Fred Murdock, recordemos, se fue a vivir con la comunidad y al cabo de un tiempo en el que llegó a soñar como los nativos, fue iniciado por el brujo. Al regresar a la universidad le comunicó a su

17 Trabajos como los de Martin (1990) o Castillo (2003) tratan sobre la relación de Borges con el escepticismo. 
tutor "que sabía el secreto y que había resuelto no publicarlo" y tuvieron el siguiente diálogo:

- ¿Lo ata su juramento? - preguntó el otro.

- No es ésa mi razón - dijo Murdock. En esas lejanías aprendí algo que no puedo decir.

- ¿Acaso el idioma inglés es insuficiente? -observaría el otro.

- Nada de eso, señor. Ahora que poseo el secreto, podría enunciarlo de cien modos distintos y aun contradictorios. No sé muy bien cómo decirle que el secreto es precioso y que ahora la ciencia, nuestra ciencia, me parece una mera frivolidad.

Agregó al cabo de una pausa:

- El secreto, por lo demás, no vale lo que valen los caminos que me condujeron a él. Esos caminos hay que andarlos.

El profesor le dijo con frialdad:

- Comunicaré su decisión al Concejo. ¿Usted piensa vivir entre los indios?

Murdock le contestó:

- No. Tal vez no vuelva a la pradera. Lo que me enseñaron sus hombres vale para cualquier lugar y para cualquier circunstancia.

Tal fue, en esencia, el diálogo. Fred se casó, se divorció y es ahora uno de los bibliotecarios de Yale (1974: 990).

La imposibilidad de comunicación (como una forma de representación) ha sido trabajada por el psicoanálisis y por la teoría política. La noción de lo Real como lo que resiste a la significación, lo que no puede ser simbolizado, ha sido integrado a la teoría de la ideología (Žižek 1992) y la teoría de la hegemonía (Laclau 2002). Ernesto Laclau, en "Sobre nombres de Dios", perfila una respuesta en la retórica (y el discurso místico) como un elemento necesario para construir la representación que, al modo borgeano en "Kafka y sus precursores" o "El escritor argentino y la tradición", termina por constituir lo que quiere representar (en una función netamente ideológica). La alternativa es acatar la sentencia de Wittgenstein ${ }^{18}$ del Tractatus, "Todo aquello que puede ser dicho, puede decirse con claridad: y de lo que no se

18 Para un estudio de la relación de Borges con Wittgenstein véase Almeida (1997) y Mualem (2002a y 2002b). 
puede hablar, mejor es callarse", o como Heidegger, ${ }^{19}$ contemplar la vía de acceso al ser en la poesía, u otra forma de arte, el misticismo, el hedonismo o la locura. ${ }^{20}$

"Funes, el memorioso" es el texto más citado sobre la incapacidad de generalizar y el imperio de los particulares (nominalismo). Recordemos que el uruguayo Ireneo Funes tenía una memoria tan prodigiosa que albergaba la imagen de cada cosa en cada instante. El espejo aquí, obviamente, es la Fenomenología del espiritu, la parte sobre la Certeza sensible, donde dice Hegel:

El contenido concreto de la certeza sensible hace que ésta se manifieste de un modo inmediato como el conocimiento más rico e incluso como un conocimiento de riqueza infinita a la que no es posible encontrar límite si vamos más allá en el espacio y en el tiempo en que se despliega, como si tomásemos un fragmento de esta plenitud y penetrásemos en él mediante la división. Este conocimiento se manifiesta, además, como el más verdadero, pues aún no ha dejado a un lado nada del objeto, sino que lo tiene ante sí en toda su plenitud. Pero, de hecho, esta certeza se muestra ante sí misma como la verdad más abstracta y más pobre. Lo único que enuncia de lo que sabe es esto: que es; y su verdad contiene solamente el ser de la cosa. La conciencia, por su parte, es en esta certeza solamente como puro yo, y yo soy en ella solamente como puro éste y el objeto, asimismo, como puro esto (Hegel 1992: 63).

19 Borges refiere a Heidegger en "Notas sobre (hacia) Bernard Shaw": "las filosofías de Heidegger y de Jaspers hacen de cada uno de nosotros el interesante interlocutor de un diálogo secreto y continuo con la nada o con la divinidad; estas disciplinas, que formalmente pueden ser admirables, fomentan esa ilusión del yo que el Vedanta reprueba como error capital. Suelen jugar a la desesperación y a la, angustia, pero en el fondo halagan la vanidad; son, en tal sentido, inmorales" (749). Mientras que en "Guayaquil" le dedica una ironía: "Este alegato mereció la refutación decisiva de Martin Heidegger, que demostró, mediante fotocopias de los titulares de los periódicos, que el moderno jefe de Estado, lejos de ser anónimo, es más bien el protagonista, el corega, el David danzante, que mima el drama de su pueblo, asistido de pompa escénica y recurriendo, sin vacilar, a las hipérboles del arte oratorio" (1974: 1063).

20 Enrique Dussel sostiene que ante la limitación de la razón monológica e identitaria la única respuesta, la salida al atolladero que nos atormenta desde el solipsismo cartesiano, pasando por Kant y los nombrados Heidegger y Wittgenstein, es la analéctica que implica el reconocimiento del otro como una (inter)subjetividad, es decir, el conocer con otros. 
En la primera aproximación, el conocimiento sensible parece el más certero, aquel que le impide a Funes confundir el gato de las dos y media con el otro gato que sucede a las tres menos cuarto. No obstante, cuando Hegel examina el problema con mayor detalle juzga esa aproximación abstracta y pobre. La memoria total de Funes le impide trascender ese momento inmediato de la certeza sensible. No obstante, contra sus alter escépticos, Borges advierte en "El idioma analítico de John Wilkins" que "La imposibilidad de penetrar el esquema divino del universo no puede, sin embargo, disuadirnos de planear esquemas humanos, aunque nos conste que estos son provisorios" (1974: 708). ${ }^{21}$ También en "El Aleph" hay una alusión (y una vaga esperanza) de decir la infinitud aunque la empresa misma esté en cuestión:

Todo lenguaje es un alfabeto de símbolos cuyo ejercicio presupone un pasado que los interlocutores comparten; ¿cómo transmitir a los otros el infinito Aleph, que mi temerosa memoria apenas abarca? Los místicos, en análogo trance, prodigan los emblemas: para significar la divinidad, un persa habla de un pájaro que de algún modo es todos los pájaros; Alanus de Insulis, de una esfera cuyo centro está en todas partes y la circunferencia en ninguna; Ezequiel, de un ángel de cuatro caras que a un tiempo se dirige al Oriente y al Occidente, al Norte y al Sur (No en vano rememoro esas inconcebibles analogías; alguna relación tienen con el Aleph.) Quizá los dioses no me negarían el hallazgo de una imagen equivalente, pero este informe quedaría contaminado de literatura, de falsedad. Por lo demás, el problema central es irresoluble: la enumeración, siquiera parcial, de un conjunto infinito. En ese instante gigantesco, he visto millones de actos deleitables o atroces; ninguno me asombró como el hecho de que todos ocuparan el mismo punto, sin superposición y sin transparencia. Lo que vieron mis ojos fue simultáneo: lo que transcribiré, sucesivo, porque el lenguaje lo es. Algo, sin embargo, recogeré ("El Aleph", 1974: 625).

Ahora bien, sabemos sobre las determinantes ontológicas que parecen ser condición de posibilidad e imposibilidad del conocimiento (la infinitud) y sabemos que hay formas de conocer esa infinitud que fracasan:

21 La relación de Borges con el pragmatismo ha sido trabajada por autores como Bosteels (2007) y Dapia (2015), especialmente el capítulo 4. 
Tiznacán, El Minotauro, Murdock, el propio Borges en el Aleph son prueba de ello. Pero, y de allí el tamaño de nuestra esperanza, ¿cómo pensar la multiplicidad? ¿Cómo recoger algo? y ¿cómo comunicar eso? Sobre Funes, dice Borges, "Sospecho, sin embargo, que no era muy capaz de pensar. Pensar es olvidar diferencias, es generalizar, abstraer. En el abarrotado mundo de Funes no había sino detalles, casi inmediatos" (1974: 490). Hegel nos diría que en ese particular se encuentra un mero esto, que es una forma "abstracta" en un sentido diferente al de Borges, que de alguna manera recuperará Marx con la idea de ascender de lo abstracto a lo concreto. Para Hegel es abstracta porque está desprendida de las determinaciones, de la totalidad. En este sentido, vuelve Borges, ahora sí más hegeliano: "Este monismo o idealismo total invalida la ciencia. Explicar (o juzgar) un hecho es unirlo a otro" ("Tlön, Uqbar, Orbis Tertius", 1974: 436). Y unir hechos (procesos) es un modo de configuración de una objetividad a partir de la intervención del sujeto. El agua para nuestro molino nos lleva a la siguiente sección.

LA CONSTRUCCIÓN DEL OBJETO:

ENTRE ALEPH, TIGRES Y MAPAS

La construcción del objeto en "El Aleph" está centrada en la postura. Como hemos señalado, a partir de un lugar y en una ubicación desde la que puede apreciarse el contenido del universo en un solo punto "Aleph es uno de los puntos del espacio que contienen todos los puntos [...] el lugar donde están, sin confundirse, todos los lugares del orbe, vistos desde todos los ángulos" (1974: 623), Carlos Argentino Daneri le dice a Borges que para ver el Aleph es indispensable adoptar una posición "decúbito dorsal", "inmóvil" "en un sitio preciso", indicaciones que a Borges le parecían ridículos requisitos, claro, antes de tener la revelación. Allí, y desde allí, le fue posible ver inmediatamente el universo ¿Qué le queremos hacer decir a Borges?, que para iniciar el proceso de construcción del 
conocimiento es necesario asumir cierta postura. Hugo Zemelman (1992) llamó "colocación epistémica" en su noción de "el método como postura":

el pensar histórico es la capacidad de complementar el simple acto de pensar circunscrito a los marcos de la predicación de objetos, es el rompimiento de los límites en la búsqueda de lo inédito. Colocarse ante las circunstancias es la disposición y capacidad para desplegarse conforme a un sentido, un para qué, que influye sobre la construcción de conceptos en torno a la realidad externa. Significa romper con los contenidos ceñidos a los límites para dar cuenta de lo real como espacio de sujetos: pensar desde el momento que obliga a hablar también de sus aperturas, lo que alude al movimiento de lo producido como siendo lo constituyente de éste y que transformamos en el ángulo para considerar el momento sin restringirnos a sus estructuras cerradas. De ahí que cuando hablamos de inconformarnos con una situación suponemos verla en sus posibilidades de desenvolvimiento, que requieren la presencia del proyecto desde el cual se leen y determinan sus potencialidades (Zemelman 2011: 34).

La misma etimología de la palabra método, lo insinúa. "Método", refiere Enrique Dussel (1998), proviene de "Metá-ódos", que traduce como "subir por el camino". Este transitar un sendero requiere de cierta posición del sujeto que se constituye también en ese acto e instaura condiciones del provenir como el horizonte. En palabras de Zemelman, "el método, antes que privilegiar la construcción de un objeto con determinadas funciones cognitivas, constituye una postura para reconocer situaciones contextuales que sean posibles de proceder a descomponer en objetos" (2006: 40). Esta colocación genera una tensión porque "Si el espacio es infinito estamos en cualquier punto del espacio. Si el tiempo es infinito estamos en cualquier punto del tiempo" ("El libro de arena"); pero a la vez ese cualquier punto es un punto. Enrique Dussel (1998) también repara en la posición desde donde se piensa. En efecto, lo hacemos no desde cualquier punto del universo sino desde un lugar producido por la totalidad como resultado de detener parcialmente la infinitud y producir un orden. La colocación permite un punto de vista que, por supuesto, inhibe otros. Acostado en el sótano, para Borges "Cada cosa (la luna del espejo, digamos) eran infinitas cosas, porque yo claramente la veía desde 
todos los puntos del universo" (1974: 625), lo que provocaría el "efecto Funes". Construir el mejor lugar para mirar lo que nos interesa es parte del posicionamiento, la renuncia a verlo todo, la tragedia. Pero, ¿quién quiere verlo todo? ¿Quién quiere ser Funes y sufrir de insomnio?

En el campo de las ciencias sociales esta construcción de una posición tiene sus particularidades. La misma noción de campo ya remite a ciertas reglas, lugares y procedimientos establecidos. En efecto, quien se aboca a producir un conocimiento en el marco de una tesis de licenciatura, de grado o de posgrado o en instancias profesionales de las ciencias sociales, se encuentra con ciertos procedimientos cuya validez contempla disposiciones burocráticas, normativas ministeriales y otras delicias, además del juicio experto de directores y tribunales inquisidores y evaluadores. Eso no garantiza la calidad del conocimiento (en el caso de que algo así pudiera establecerse) como tampoco lo hace la empresa librepensadora, autónoma (en el sentido de producir las propias normas) individual o colectiva, hedonista o comprometida de quien renuncia - seguramente con buenos motivos- a las prisiones de la torre de marfil. No obstante, conviene recordar que la concepción del sujeto político del pensamiento posfundacional, puede ser invocada, por analogía, para referir al sujeto cognoscente:

Y está claro también que, si por un lado el sujeto no es externo respecto de la estructura, por el otro se autonomiza parcialmente de esta en la medida en que él constituye el locus de una decisión que la estructura no determina. Pero esto significa: (a) que el sujeto no es otra cosa que esta distancia entre la estructura indecidible y la decisión; (b) que la decisión tiene, ontológicamente hablando, un carácter fundante tan primario como el de la estructura a partir de la cual es tomada, ya que no está determinada por esta última; (c) que si la decisión tiene lugar entre indecidibles estructurales, el tomarla sólo puede significar la represión de las decisiones alternativas que no se realizan. Es decir que la "objetividad" resultante de una decisión se constituye, en su sentido más fundamental, como relación de poder (Laclau 2000: 47).

En este punto es posible distinguir analíticamente dos dimensiones: la de las ciencias sociales académicas y profesionales por un lado y la del 
pensamiento político por otro. Esta distinción puede subvertirse en la propia producción de conocimiento (colocamos allí una infundada apuesta). El academicismo y la profesionalización no significan mayor rigurosidad y, mucho menos, productividad como pensamiento político si entendemos éste como aquel capaz de ser parte de las disputas por el orden vigente, de activar potencialidades, como dice Hugo Zemelman (1992). Boaventura de Sousa (2009) propuso la idea de ecología de saberes para valorizar las múltiples formas de producción de conocimiento y combatir el epistemicidio al tiempo de buscar las traducciones de los conocimientos. Estos aspectos también están contemplados en el método como postura y la construcción de una subjetividad epistémica.

Pero volvamos a Borges. En "El Aleph" la clave está en la postura y en el acceso a los dos o tres centímetros de diámetro que contienen todo el universo. En "La escritura del Dios", el problema de intraducibilidad de la experiencia mística existe pero es trabajada de un modo que nos interesa destacar, podemos decir, a partir de un isomorfismo condensado entre palabra y universo:

Consideré que aun en los lenguajes humanos no hay proposición que no implique el universo entero; decir el tigre es decir los tigres que lo engendraron, los ciervos y tortugas que devoró, el pasto de que se alimentaron los ciervos, la tierra que fue madre del pasto, el cielo que dio luz a la tierra. Consideré que en el lenguaje de un dios toda palabra enunciaría esa infinita concatenación de los hechos, y no de un modo implícito, sino explícito, y no de un modo progresivo, sino inmediato. Con el tiempo, la noción de una sentencia divina parecióme pueril o blasfematoria. Un dios, reflexioné, sólo debe decir una palabra, y en esa palabra la plenitud. Ninguna voz articulada por él puede ser inferior al universo o menos que la suma del tiempo. Sombras o simulacros de esa voz que equivale a un lenguaje y a cuanto puede comprender un lenguaje son las ambiciosas y pobres voces humanas, todo, mundo, universo (1974: 598).

La operación que nos interesa destacar es la condensación de lo múltiple, la historicidad relacional contenida que no es arbitraria en un nombre, que tampoco es arquetípico de la cosa, como dice en "El Gólem", porque en la palabra tigre que refiere a ese tigre no está contenida cual- 
quier cosa sino una multiplicidad, ese objeto (y su nombre), según a Marx, es "síntesis de múltiples determinaciones" que hicieron que ese tigre sea ese tigre..$^{22}$ De igual modo lo enuncia en "El Zahir":

Dijo Tennyson que si pudiéramos comprender una sola flor sabríamos quiénes somos y qué es el mundo. Tal vez quiso decir que no hay hecho, por humilde que sea, que no implique la historia universal y su infinita concatenación de efectos y causas. Tal vez quiso decir que el mundo visible se da entero en cada representación, de igual manera que la voluntad, según Schopenhauer, se da entera en cada sujeto (1974: 595).

¿Cómo producir (o comunicar) aquello que Marx llamó lo concreto pensado que contiene las determinaciones múltiples de la realidad sin ser el sujeto cognoscente infinito o eterno? Para abordar esta cuestión, por la negativa, podemos invocar dos estrategias. La primera, la búsqueda de una descripción isomórfica que procura capturar la elusiva totalidad mediante "la acumulación caótica de un catálogo heterogéneo de elementos" (Alonso 2005: 440). El acto de intuición inmanente busca ponerse en un lenguaje que es por definición diacrónico, allí la tragedia. Análogamente, en el breve (y célebre) texto en "Del rigor en la ciencia" donde Borges refiere a un imperio en que los cartógrafos buscaban tal perfección en su arte que acabaron por hacer un mapa que coincidía puntualmente con ese imperio. El resultado, naturalmente, fue un producto inservible ya que la función del mapa es la reducción de la escala para los fines de guía.

La condensación y la escala son claves a la hora de construir objetos en el campo de las ciencias sociales. No se trata de "recortar" dejando procesos, dimensiones o determinaciones constitutivas sino de incluirlas de

22 La figura del tigre aparece también en "El Zahir": "un faquir musulmán había diseñado (en bárbaros colores que el tiempo, antes de borrar, afinaba) una especie de tigre infinito. Ese tigre estaba hecho de muchos tigres, de vertiginosa manera; lo atravesaban tigres, estaba rayado de tigres, incluía mares e Himalayas y ejércitos que parecían otros tigres". La reiteración de la figura tigre es referida por Borges en una entrevista en la que afirma que se inspiró en el parecido del pelaje de un jaguar con la escritura, aunque aclara que es específicamente un jaguar lo que lo inspira para situar la historia en México (una de las pocas, si no la única, historia situada alli); https://www. youtube.com/watch? $=$ egf5maVNYGA. 
tal modo que éstas se contengan en el constructo capaz de ser abordado en la tarea de investigar y además de ser útil en su función epistémica. El desafío, claro está, es la definición de ese objeto bajo la lógica de la inclusión determinada que no implica sumar dimensiones sino en la medida de su "necesidad" para dar cuenta del objeto en un juego de delimitación y articulación (Zemelman 2009). El problema, en otras palabras, es cómo incluir las dinámicas tendencialmente infinitas y en movimiento, múltiples dimensiones y escalas, en un constructo analítico (y en el lenguaje). Algo análogo plantea Luhmann sobre el sentido: "El sentido es entonces -y hacemos hincapié en lo paradójico de la formulación- un contexto de remisiones infinito, esto es, indeterminable, que puede hacerse accesible y reproducirse en forma determinada" (Luhmann 2007: 32). Esto es, claro, la reducción de la complejidad o, quizás con mayor precisión, la condensación de la complejidad en un proceso de subsunción.

En este esfuerzo por incluir dimensiones de la realidad en el objeto es, por supuesto, fundamental la cuestión de la temporalidad, los múltiples tiempos y la historicidad, aspectos que por suerte obsesionaban a Borges: "El tiempo es un problema para nosotros, un tembloroso y exigente problema, acaso el más vital de la metafísica" dice en "Historia de la eternidad" (1974: 353). Mucho, como de cada tópico borgeano, se ha escrito sobre el tiempo y Borges. No desconocemos que las ideas del eterno retorno y la circularidad cronológica fueron fecundos estímulos literarios cuya presencia rastreó en la historia de la filosofía como lo expone en "Nueva refutación del tiempo": "El tiempo es como un círculo que girara infinitamente: el arco que desciende es el pasado, el que asciende es el porvenir; arriba, hay un punto indivisible que toca la tangente y es el ahora" (1974: 770); obviamente en "El tiempo circular"; y "La doctrina de los ciclos" y el poema "La noche cíclica". No obstante, vamos a dirigir la cara de nuestro espejo a otra concepción de la temporalidad contenida con evidencia deslumbrante en "El Jardín de los senderos que se bifurcan":

El jardín de los senderos que se bifurcan es una enorme adivinanza, o parábola, cuyo tema es el espacio; esa causa recóndita le prohíbe la mención de su nombre. Omitir siempre una palabra, recurrir a metáforas ineptas 
y a perífrasis evidentes, es quizá el modo más enfático de indicarla. Es el modo tortuoso que prefirió, en cada uno de los meandros de su infatigable novela, el oblicuo Ts'uiPên. He confrontado centenares de manuscritos, he corregido los errores que la negligencia de los copistas ha introducido, he conjeturado el plan de ese caos, he restablecido, he creído restablecer, el orden primordial, he traducido la obra entera: me consta que no emplea una sola vez la palabra tiempo. La explicación es obvia: El jardín de los senderos que se bifurcan es una imagen incompleta, pero no falsa, del universo tal como lo concebía Ts'uiPên. A diferencia de Newton y de Schopenhauer, su antepasado no creía en un tiempo uniforme, absoluto. Creía en infinitas series de tiempos, en una red creciente y vertiginosa de tiempos divergentes, convergentes y paralelos. Esa trama de tiempos que se aproximan, se bifurcan, se cortan o que secularmente se ignoran, abarca todas las posibilidades. No existimos en la mayoría de esos tiempos; en algunos existe usted y no yo; en otros, yo, no usted; en otros, los dos (1974: 479).

Para nosotros, la temporalidad social y su relación con el proceso de investigación es de sumo interés porque permite apartarnos de la compulsión de las ciencias sociales por considerar una sola dimensión del tiempo bajo la idea de que éste es una sucesión lineal de eventos. La temporalidad de los procesos sociales puede considerarse múltiple, tanto en su dimensión diacrónica como en la sincrónica, en las que juegan las figuras clásicas cronos, kairós y aión. La temporalidad de pasado, presente y futuro, a la que Borges en el poema a Heráclito refiere - “Qué trama es ésta del será, del es y del fue?" (1974: 979) — se traduce en abordar los procesos constituyentes de dinámicas que cristalizan en una particular estructuración del orden y su régimen (económico, político, cultural, etc.), y que lo determinan (son condición de posibilidad de la acción en el imposible presente). La dimensión plural del pasado se restituye en las figuras de las memorias constitutivas, capaces de reconfigurarse como parte de lo que Ricoeur llamó identidad narrativa, una dimensión del sujeto. El presente, por su parte, siempre huidizo, es el espacio de la acción que se vuelve performativa para el sujeto y constitutiva al actualizar potencialidades contenidas. Lo dice Borges en "El jardín de los senderos que se bifurcan": "el provenir ya existe", porque está contenido como posibilidad no (sólo) lógica sino real, como potencia, pero iquién puede determinar 
lo efectivamente posible cuando las condiciones de su posibilidad están en perpetuo movimiento? La acción política es la que actualiza algunos de esos innumerables futuros posibles, de este modo transforma la utopía en historia (Zemelman 1989), actualiza aquello que es un "todavía-no" (Bloch 1980). Por un lado hace posible lo que parece imposible (activa lo político) por otro trabaja con la historicidad sedimentada. El desafío de la praxis es, entonces, evidente y la historia se transforma en un criterio de verdad.

No debemos olvidar, además, que tenemos la temporalidad sincrónica, todos los tiempos al mismo tiempo, como en el Aleph. Los tiempos macroestructurales como los de la colonialidad, el capitalismo, el neoliberalismo, los tiempos estatales, comunitarios, familiares, íntimos. Múltiples tiempos que configuran los procesos que nos proponemos estudiar y que confluyen en espacios (también multiescalares). Al fin y al cabo, "El jardín de los senderos que se bifurcan es una enorme adivinanza, o parábola, cuyo tema es el espacio" (1974: 479) y la clave, presente por la ausencia de su nombre, es el tiempo.

EPÍLOGO

Hemos jugado con los espejos, desoyendo aquello de que son abominables (Historia universal de la infamia) y que tienen algo de monstruoso ("Tlön, Uqbar, Orbis Tertius") o tal vez por eso mismo. Para nosotros los textos borgeanos son un reservorio de metáforas para pensar problemas ontológicos. Allí, como dice Ricardo Piglia (1997), hemos reparado en los usos de Borges en un doble sentido. Por un lado explorando los usos que hace de ciertas metáforas constitutivas de su universo literario y, por otro, hemos usado a Borges para abordar los problemas de la epistemología de las ciencias sociales inscritos en un terreno contemporáneo.

En nuestro recorrido hemos reflejado en los textos borgeanos la tesis ontológica posfundacional. El infinito, capaz de jaquear la plenitud por su persistencia y la ausencia de un orden (y un arkbé) son ideas filosóficas que Borges pone al servicio de sus textos. La pregunta por ordenadores 
superiores, por las codificaciones establecidas y los decodificadores obstinados, a veces condenados al fracaso o, peor aún, capaces de acceder a secretos que no pueden ponerse en lenguaje. Las ciencias sociales son un intento de acceder a estos misterios. Ello implica asumir los desafíos de pensar la indeterminación, el infinito y el tiempo. La construcción del objeto como intervención del sujeto que investiga supone lidiar con la complejidad, con el movimiento, con la multidimensionalidad de una realidad que se pretende incluir en el objeto como estrategia de investigación, como construir un pequeño Aleph particular. Una reconstrucción sintética de los procesos constitutivos de la realidad social. Incluir la realidad múltiple en el objeto, como exigencia epistémica, convoca también la función problematizadora (como descomposición de entradas posibles) y la articulación de los determinantes históricos. Teoría y metodología son, aquí, parte del proceso al servicio de las preguntas de investigación. Pero ese, ese es otro laberinto, de cuyo tránsito hoy nos abstendremos.

\section{BiBLIOGRAFíA}

ALAZRAKI, JAIME. "Tlön y Asterión: metáforas epistemológicas". Jorge Luis Borges. Madrid: Taurus, 1987.

AlmeidA, Ivan. "Lillustre incertitude. Borges, Wittgenstein et l'énonciation philosophique". Variaciones Borges: revista del Centro de Estudios y Documentación Jorge Luis Borges 3 (1997): 81-99.

Alonso, Carlos. "Borges y la teoría". MLN, 120/2 (2005): 437-456.

BEnavides, Manuel. "Borges y la filosofía". Cuadernos Americanos 444. 1 (1987): 18-126.

."Borges y la metafísica". Cuadernos Hispanoamericanos 565-566 (1997): 247-268.

BORGES, Jorge LuIS. Obras completas (1923-1972). Buenos Aires: Emecé, 1974.

Obras completas (1975-1988). Buenos Aires: Emecé, 1996. 
Bossart, William. Borges and Philosophy: Self, Time, and Metaphysics.

Nueva York: Peter Lang, 2003.

Bosteels, BRuno. "Borges as Antiphilosopher". Vanderbilt e-Journal of Luso-Hispanic Studies 3 (2007): 23-31.

. "The Truth is in the Making: Borges and Pragmatism". Romanic Review 98. 2/3 (2007): 135-151.

Castillo, Jorge Luis. "Pierre Menard and the School of the Skeptics". Hispanic Review 71.3 (2003): 415-428.

CASTORIADIS, CORNELIUS. La institución imaginaria de la sociedad. Buenos Aires: Tusquets, 2007.

DAPIA, SiLVIA, "Borges Social Order and Human Action". Variaciones Borges: revista del Centro de Estudios y Documentación Jorge Luis Borges 36 (2013): 125-154.

. "'This is not a Universe': an Aproach to Borges's 'thlon, Uqbar, Orbis Tertius"'. Chasqui 26. 2 (1997): 94-107.

- Jorge Luis Borges, Post-analytic Philosophy and Representation. Nueva York: Routledge, 2015.

Deleuze, Gilles y Felix GuatTARI. Mil mesetas. Valencia: Editorial Pre-textos, 1995.

DuSSEL, ENRIQUE. Ética de la liberación. En la edad de la globalización y de la exclusión. Madrid: Trotta, 1998.

FouCAult, Michel. Las palabras y las cosas. México: Siglo XXI, 1989.

HeGel, GEORG. W. F. Fenomenología del espiritu. México: FCE, 1992.

LACLAU, ERNESTO. Nuevas reflexiones sobre la revolución de nuestro tiempo. Buenos Aires: Nueva Visión, 2000.

- "Sobre los nombres de Dios". Misticismo, retórica y política.

Buenos Aires: FCE, 2002.

LaWson, Curve et al. (eds.). Contributions to Social Ontology. Londres y

Nueva York: Routledge, 2013.

LEMA-HinCAPIÉ, ANDRÉS A. "Philosophia ancilla litterarum? El caso Borges para el pensamiento francés contemporáneo". Ideas y Valores 54. 129 (2005): 21-33. 
, "Borges y la filosofía occidental. Algunos momentos de la crítica”. Praxis Filosófica 14 (2011): 99-114.

LEVINAS, EMmanuel. Totalidad e infinito: ensayo sobre la exterioridad. Salamanca: Sígueme, 2002.

Luhmann, NikLAS. La sociedad de la sociedad. México: Universidad Iberoamericana, 2007.

Marchart, Oliver. Post-foundational Political Thought: Political Difference in Nancy, Lefort, Badiou and Laclau. Edinburgh: Edinburgh University Press, 2007.

MarTín, Marina. "Visión escéptica en 'Tlön, Uqbar, Orbis Tertius”. Revista de Estudios Hispánicos 24.1 (1990).

MARTín, JORGE. "Borges inominalista o antinominalista?" Variaciones Borges: revista del Centro de Estudios y Documentación Jorge Luis Borges 30 (2010): 183-198.

MateOs, Zulma y ARTURO GarCíA. La filosofía en la obra de Jorge Luis Borges Buenos Aires: Biblos, 1998.

MARX, KARL. Contribución a la crítica de la economía política. México: Siglo XXI, 1980.

Mualem, SHLOMy. "Borges and Wittgenstein on the Borders of Language: the Role of Silence in 'The God's Script' and the Tractatus Logico-Philosophicus". Variaciones Borges: revista del Centro de Estudios y Documentación Jorge Luis Borges 14 (2002a): 61-78.

. "What Can Be Show Cannot Be Said. Wittgenstein's Doctrine of Showing and Borges' 'The Aleph"'. Variaciones Borges 13 (2002b): 51-56.

Olaso, EzEQuiEL DE. Jugar en serio: aventuras de Borges. México: Paidós / UNAM, 1999.

Pantoja MelÉndez, Josefina. "El tiempo en un cuento de Borges: 'El jardín de senderos que se bifurcan"'. Thémata: Revista de Filosofía 45 (2012): 303-318.

Piglia, RiCARDO. "Los usos de Borges. Entrevista realizada por Sergio Pastormerlo". Variaciones Borges: revista del Centro de Estudios y Documentación Jorge Luis Borges 3 (1997): 17-27. 
PIVOT, BERNARD. "Borges oral". La Jornada Semanal, 23 de mayo de 1997. REST, JAIME. El laberinto del universo. Borges y el pensamiento nominalista, Buenos Aires: Eterna Cadencia, [1976] 2009.

SAENZ, Dalmiro, Yo también fui un espermatozoide. Buenos Aires: Torres Agüero, 1983.

SARLO, BeATRIZ. Borges, un escritor en las orillas. Buenos Aires: Siglo XXI, 2007.

STEWART, Jon. "Borges' Refutation of Nominalism in 'Funes el memorioso'". Variaciones Borges: revista del Centro de Estudios y Documentación Jorge Luis Borges 2 (1996): 68-86.

SOUSA SANTOS, BOAVENTURA DE. Una epistemología del sur: la reinvención del conocimiento y la emancipación social. México: Siglo XXI, 2009. TORO, ALFONSO y FERNANDO TORO (eds.). Jorge Luis Borges: pensamiento y saber en el siglo XX. Frankfurt am Main: Vervuert, 1999.

VEIRAS, NORA y LEONARDO MOLEDO. "Los científicos deben asumir su compromiso social". Página/12, 7 de enero de 2008. Artículo en línea disponible en https://www.pagina12.com.ar/diario/elpais/1-97152-2008-01-07.html (Consultado el 30 de noviembre de 2018).

Zemelman, Hugo. De la historia a la política: la experiencia de América Latina. México: Siglo XXI, 1989.

"Alternativas en el método de la investigación científica ies la prueba de hipótesis el único camino?". Tratado Latinoamericano de Sociología. México: Anthropos / Universidad Autónoma Metropolitana, 2006. 39-44.

- Los horizontes de la razón: uso crítico de la teoría. Vol. 2. Barcelona: Antrophos, 1992.

- Uso crítico de la teoría. En torno a las funciones analíticas de la totalidad. México: Instituto Politécnico Nacional, 2009.

- "Implicaciones epistémicas del pensar histórico desde la perspectiva del sujeto". Desacatos 37 (2011): 33-48.

ŽižEK, SLAVOJ. Less than Nothing: Hegel and the Shadow of Dialectical Materialism. London/New York, Verso Books, 2012. 